\title{
A new partnership
}

\author{
Paul Stewart and P Reed Larsen
}

We are delighted to announce that Nature Clinical Practice Endocrinology \& Metabolism has become an official journal of the International Society of Endocrinology (ISE) with effect from this issue. The ISE was established in 1960 to advance the profession and to improve the efficiency and effectiveness of endocrinology information exchange at the international level. Its worldwide membership currently comprises 63 national societies; the total number of members from these societies exceeds 35,000 and is steadily growing. Through its national bodies, ISE reaches to all endocrinologists and associated scientific professionals working in universities, industry, government agencies and practitioners in health-care facilities.

The mission of the ISE is to disseminate knowledge of endocrinology, improve training and tackle global endocrine health issues, in part by uniting the activities of the national partners. Society activities involve coordinating and organizing international congresses and conferences. With the help of the national endocrine societies, the ISE is also reaching out to developing countries by formulating training programs. One important goal is the creation of an Endocrine Scholars program, whereby selected candidates will receive training at mentoring institutions and then return to their own countries to disseminate their knowledge. ISE also promotes the publication of books, reports and articles related to endocrinology.

The society has come a long way from the early 1960s when international standards in endocrinology were put in place. Now, 40 years later, the ISE is committed to reform

\section{The formal association with ISE synergizes perfectly with the mission of Nature Clinical Practice Endocrinology \& Metabolism}

PStewart is the Secretary-General of the International Society of Endocrinology and a Professor of Medicine and Endocrinology at the University of Birmingham, Queen Elizabeth Hospital, Birmingham, UK. PR Larsen is the Editor-inChief of Nature Clinical Practice Endocrinology \& Metabolism, Chief of the Division of Endocrinology, Diabetes and Hypertension at Brigham and Women's Hospital and a Professor of Medicine at Harvard Medical School, Boston, MA, USA.

\section{Competing interests}

The authors declared they have no competing interests.

www.nature.com/clinicalpractice doi:10.1038/ncpendmet0078 so it can better cater to the global needs of endocrinology and plans to do so through changes to its conferencing structure, closer liaison and partnership with its national constituents, and development of its website, www.endosociety.com.

From an editorial perspective, we are extremely excited about this new relationship. The formal association with ISE synergizes perfectly with the mission of Nature Clinical Practice Endocrinology \& Metabolism. Individuals belonging to ISE member organizations across the world will be able to subscribe to the journal at reduced rates, thus increasing its accessibility. In addition, the leadership of the ISE-Professors Melmed and Stewart-are already valued members of the journal Advisory Board. The editorial team will continue to welcome their counsel, not only as distinguished clinical endocrinologists, but in their new role as representatives of the international endocrine community. The feedback they will provide from this constituency will enable us to address the needs of the broadest possible endocrine audience. We are certain that these changes will facilitate our goal of providing new information in a timely fashion to all physicians involved in the practice of endocrinology. In this way, we hope to aid them in providing the highest quality of care for their patients irrespective of international boundaries. We will also collaborate with the ISE to address important endocrine issues that have global health significance, such as obesity and iodine deficiency, by disseminating new knowledge about these topics. We look forward to a stimulating and mutually productive relationship. 